\title{
A Partner Perspective on the Evolution of the Global Special Operations Forces Enterprise
}

\section{Asbjørn Lysgård and Ole Boe*}

Department of Military Strategy and Operations, Norwegian Defence Staff and Command College, Norwegian Defence University College, Norway

\begin{abstract}
The purpose of this article is to provide a perspective on the evolution of the Global Special Operations Forces Enterprise as seen from a partner perspective. The article starts with a review of the historical antecedents of Special Operations Forces since the second world war and the development of the Norwegian Special Operations Forces until today. The article then continues with a discussion of the development of the Global Special Operations Forces Network. The construction of a Special Operations Forces network and the operationalization of the Global Special Operations Forces Network is then discussed. Steps that were taken to maintain the imitative and the challenges of creating a coalition to participate in Operation Inherent Resolve is then discussed. Some conclusions regarding the coalition of the willing in relation to the Global Special Operations Forces Network are drawn, and challenges related to this is then discussed. A recommendation in view of the revealed challenges is that a beneficial step for the Global Special Operations Forces Network would be to define the organizational structure and clearly articulate it for operations at all levels.
\end{abstract}

Keywords: Special operations forces; Global special operations forces network; Norwegian special operations command, Network; Operation inherent resolve

\section{Introduction}

Military leaders of all branches and departments confront foreign policy on behalf of their governments, developing capacities and resilience to win the current fight against an adversary that in many cases is unknown or has a complex leadership structure. Knowing whom to trust and who is willing to support a nation's efforts becomes important as leaders build a "coalition of the willing." Through the Global Special Operations Forces Network (GSN), Special Operations Forces (SOF) can execute integrated campaigning with partners to facilitate dialogue across borders, shortening lines of communication and continuing development of high technology solutions. As information is transmitted across the world in seconds, timely planning and coordination in support of an operation becomes more important than ever in order to protect soldiers and win the current fight. It has become apparent that the growing complexity of each mission demands an ever-increasing ability for situational awareness. The creation and implementation of the GSN by partner nations (PNs) has created cost-effective coordination solutions and, through that, increased security for deployed personnel across the globe. Moreover, enhanced understanding by political leaders and senior military officials on how to exploit the vast opportunities the GSN provides in support of creating a coalition has yielded progress in the fight against Daesh. Daesh is a name used to refer to ISIS/ISIL, the radical Sunni Muslim organization. The use of the name Daesh is said to delegitimize the group's claim to be an "Islamic state" [1].

\section{Close Ties and Closed Communities}

During the German invasion of Norway in 1940, the Norwegian Armed Forces lacked everything from timely plans and defense preparations to strategic guidance on how to fight a war. On the other hand, diplomatic ties, specifically between Norway, the United Kingdom, and the United States, were steadfast and soon proved their importance. Throughout the German occupation of Norway, close ties between Norway and her allies developed, allowing the Norwegian royal family to settle both in London and Washington, D.C., King Haakon
VII of Norway fled to London, as did the Norwegian government, thereby escaping the German invasion. Their freedom and survival became immensely important, as did the need for unconventional and Special Operations Forces.

In 1940, an organization named the Special Operations Executive (SOE) was established in Great Britain with the support of Sir Winston Churchill and approval by the British Cabinet. Through this organization, the first Norwegian SOF unit, the Norwegian Independent Company No.1(NOR.I.C.1, later known as Company Linge), was created [2]. Concurrently, the United States was setting up the Office of Strategic Services (OSS) under the leadership of William J. Donovan, an effort that benefitted from the support of British Special Intelligence Services (SIS) and the SOE [3]. These establishments of small units with reach-back capabilities to Whitehall and Washington, D.C., are known to be the first official cooperation between SOF units, creating a network for agents across the globe [3]. In 1945, the OSS sent Major William Colby, who would later become the first director of the Central Intelligence Agency, to lead the Norwegian Special Operations (NORSO) Group in Norway and to conduct sabotage and collaborate with organized Norwegian resistance and guerillas [4]. For a small nation like Norway, the connections and personal relations that were established with colleagues from the USA and United Kingdom during the Second World War set the foundation for the future development of SOF.

Norway, however, following the Second World War, disbanded all its SOF units to prioritize a larger conventional force structure

*Corresponding author: Ole Boe, Department of Military Strategy and Operations, Norwegian Defence Staff and Command College, Norwegian Defence University College, Norway, Tel +47 2309 5807; E-mail: olegboe@kravmag.no

Received November 07, 2017; Accepted November 14, 2017; Published November 21, 2017

Citation: Lysgård A, Boe O (2017) A Partner Perspective on the Evolution of the Global Special Operations Forces Enterprise. Arts Social Sci J 8: 313. doi: 10.4172/2151-6200.1000313

Copyright: ( 2017 Lysgård A, et al. This is an open-access article distributed under the terms of the Creative Commons Attribution License, which permits unrestricted use, distribution, and reproduction in any medium, provided the original author and source are credited. 
to meet the Soviet threat. The legacy of OSS and SOE was still present though, especially in the reserves and the Norwegian Home Guard. Finally, almost a decade after the war, the Norwegian Armed Forces started to reinvest in SOF. In 1953, the Navy established the first teams of Frogmen and, in 1962, the Army established Horens Fallskjermjegerskole (HFJS), the Army's Commando School, to train long-range reconnaissance units for parachute insertion behind enemy lines. During the Cold War, USA SOF worked closely with HFIS to shape the battlefield, fighting off a potential threat from the East. Throughout the Balkan wars and the Kosovo crisis, Norwegian SOF became an expeditionary strategic deployable force, which later developed into Horens Jegerskole/Forsvarets Spesialkommando, the predecessor of the current strategic command [5].

The Norwegian Special Operations Command (NORSOCOM) was established on January 1, 2014, when its first commander, Rear Admiral Nils Johan Holte, took command of the two tactical Norwegian SOF units, Forsvarets Spesialkommando (FSK), and the Navy SOF unit Marinejegerkommandoen (MJK) [6]. Since that time, the NORSOCOM commander and his staff have strengthened the long-established relations between the different SOF units around the world. Within NORSOCOM, there are departments specifically tasked with handling international relations and interagency coordination and connecting the lines between various organizations and government entities. NORSOCOM is represented within the Norwegian National Command Authority, NATO command, and at USA. Special Operations Command (USSOCOM, commonly referred to as SOCOM) by a wide range of liaison officers (LNOs). This forward presence is a part of the global SOF community, representing the NORSOCOM commander in many SOF venues, organizations, and arenas. Many LNOs report directly to the Commander NORSOCOM or the Chief of Defense as needed or required.

The long-term relationships created during the interactions of agents and commandos during the Second World War never ceased to grow and develop. The networks continued to expand, culminating in the current fights in Afghanistan and Iraq, where this multi-faceted network of professionals has proven its value to military, civilian, and political leaders. The trust that has been built within the group of individuals that belong to the SOF community is immeasurably strong. However, new technology and the methods of modern, sophisticated warfare have made it clear that to win the current fight, SOF operations require non-SOF support [7]. The importance of a broad coalition and mutual support has become more evident as international matters create important concerns for politicians. A global SOF network can accelerate development, create strategic options for policymakers, and provide the best military, and sometimes grass-roots political advice, in a timely manner to strategic leaders.

\section{The Global Special Operations Forces Network}

SOF depend on continuous development to remain relevant, and one way to develop its relevance is through close interactions with other nations' SOF. Thus, SOF networks aid in both tactical development and fostering strategic partnerships. A SOF network among friends and allies across the globe serves many interests [5]. It is in the interest of small states, as well as in the interest of regional security partners, to develop the Global SOF Network. In this context, networks of the GSN include an understanding of SOF-likeorganizations, operational support requirements, communication technology, techniques, and procedures.

When Admiral William $\mathrm{H}$. McRaven assumed command of USSOCOM on 8 August 2011, he envisioned and initiated a formalization of the GSN [8]. The idea was to establish a peacetime network of SOF throughout the globe to build on the experience gained from over a decade of war. Through a global SOF network, SOCOM would enable SOF allies around the world to establish and sustain partnerships, very similar to how NATO Special Operations Headquarters has organized SOF cooperation in Europe.

To further take advantage of these regional and global networks, small nations need a dedicated, strategic SOF element with the authority and resources to operationalize initiatives [9]. The future of the GSN should therefore focus on the ability of individual states to establish strategic leadership of their SOF, best addressed through a dedicated SOF element, especially for small states [5]. Smaller states with correspondingly smaller military staffs can only afford a single "node" or organizational entity to coordinate across all of the military elements. A central organization creates a single, strategic SOF Enterprise with both efficiency (effective use of resources) and effectiveness (being able to quickly synthesize and coordinate from a central point). Tactical units, however, must be empowered to practice "mission command" or make decisions based upon intent when they are confronted with changes in their environment. This suggests that centralizing at the strategic level and decentralizing-at least from a decision-making standpoint-at the tactical level provides a "best practices" solution [10]. In effect, this describes the US mission-command philosophy in action. This is a subtle but extremely important point that must not be lost. Mission Command also requires the commander to be comfortable with risk and puts a priority on selecting excellent operators that are not only tactically superior but also have a strategic mindset.

The strategy of the NORSOCOM commander is investing in the development of junior and mid-level officers in order to expect better decisions in the field based upon his intent, thereby "buying down this risk" in advance through education, training, and development. This investment in junior officers' strategic abilities aligns with Admiral McRaven's 2011 initiation of rigorous process assessment for how to best position and sustain USA SOF to meet current and future challenges to US national security. Guiding the assessments was an assumption that "there are no local problems [11]. solutions must therefore come through cooperation, collaboration, and building capacity with PNs. McRaven referred to the product of that assessment as the "Global SOF Network strategy [12]. The future of SOF, in accordance with Presidential direction and as envisioned in the GSN initiative, lies in joint operations, with USA SOF operating by, with, and through its interagency and international partners as the Global SOF Network.

\section{Building a Network}

In 2006, Admiral McRaven was tapped to lead Special Operations Command Europe (SOCEUR), based in Stuttgart, Germany. Under his initiative as Commander SOCEUR, he established the NATO SOF Coordination Center (NSCC), enhancing and integrating the efforts of all NATO SOF. In 2010, the NSCC evolved to become the NATO SOF Headquarters (NSHQ). To support this NATO initiative, small states like Norway contributed personnel to the Headquarters from the very start [5]. NSHQ was viewed as a mechanism to enhance SOF cooperation and coordination, and to give small states a common arena to address strategic SOF-specific issues within the NATO alliance. Today NSHQ is collocated with Supreme Headquarters Allied Powers Europe (SHAPE) and, among several other roles, has become 
the center for coordination among NATO allies in the development of SOF [13].

When Admiral McRaven took over as Commander of SOCOM, he drew on the success of NSHQ, along with his service as the eleventh commander of Joint Special Operations Command. Admiral McRaven also spent much time in Afghanistan, where operations intensified on his watch. His experiences relying on cooperation with interagency and coalition forces made it clear that a network similar to that formalized in NSHQ needed to be built between SOCOM and its international SOF partners to ease the future planning and coordination of US operations with coalition support.

\section{Operationalizing the GSN}

A series of strategic meetings between McRaven and other countries' SOF commanders and Chiefs of Defense resulted in the planning and formation of national strategic SOF commands like NORSOCOM in Norway [14]. A SOCOM-like structure is necessary to take full advantage of the opportunities NSHQ and SOCOM provide in terms of regional SOF cooperation. Interoperability; common command and control structures; and operational-level, deployable, joint, and combined SOF headquarters are all examples of the issues that were considered in establishing the GSN. Knowing how to address lessons learned and integrating knowledge from previous operations are ideas that must be addressed through strategic commands. Coordinating unity of interest and community of action is a pillar of the GSN and a vast improvement on the complexity of fighting information sharing, intelligence, and foreign disclosure issues.

In spite of this, location, space, limitation of access, and distribution of classified documents turned out to be a long and painful process in the development of the GSN. It was not until May 2014, when the transition of the global SOF operational planning team (OPT), led by US Army Colonel Stuart Bradin, stood up the J3-International (J3-I) at SOCOM, that the global SOF network truly began to operationalize. It was during this time that the USA, along with all of its equivalent international partners in the J3-I, came together to work directly alongside one another in a horizontal, agile, and cooperative organization inside the SOCOM headquarters. The new location provided an open workspace where PNs could communicate with national commands through both national and NATO communication systems. The flexible, open workspace community allowed information to flow quickly and easily, as opposed to the episodic and fractured manner consistent with assigning separate rooms or workspaces to each nation. Additional rooms were provided with the new arrangement to facilitate one-on-one discussion when needed, and large areas could be cleared for briefings of different classifications, pending attendance and content of the PN discussions [15].

J3-I was tasked to integrate PNs within the GSN. Its goals and primary functions were to facilitate enhanced decision-making for USA and global SOF commanders, integrate PNs into SOCOM processes, increase inter-operability, improve staff processes to better inform strategic planning and resourcing, and enhance and accelerate the development of multilateral courses of action and cooperation among global SOF partners [16].

As Admiral McRaven prepared to transition command to his successor, the fifth International Special Operations Forces (ISOF) Conference took place in Tampa, Florida. The theme of the conference was "Strengthening the Global SOF Network," and SOF representatives and commanders from more than 80 countries participated. The conference brought forth a new issue not explored in depth in previous conferences: SOCOM's network strategy, which emphasized a comprehensive whole-of-government approach to coordinate agencies, departments, and PN SOF integration into SOCOM, did not fully explain how small PNs were expected to contribute to and benefit from the GSN [17].

In 1996, RAND strategists John Arquilla and David Ronfeldt proposed the concept that "It takes a network to fight networks" [18]. The idea got more attention in the aftermath of September 11, 2001:

It takes networks to fight networks. Governments that want to defend against Netwar may have to adopt organizational designs and strategies like those of their adversaries. This does not mean mirroring the adversary, but rather learning to draw on the same design principles that he has already learned about the rise of network forms in the information age. These principles depend to some extent on technological innovation, but mainly on a willingness to innovate organizationally and doctrinally, perhaps especially by building new mechanisms for interagency and multijurisdictional cooperation [19].

Within the GSN, Memoranda of Understanding (MOU) and Memoranda of Agreement (MOA) regulate the sharing of information between participating nations. The baseline that every participating nation needs to fulfill is an MOU or an MOA with the United States [17]. When this is concluded, access is granted, and J3-I capabilities enable a broad range of PN collaboration to occur on a continuous basis (USA -to-PN Bilateral, PN-to-PN Bilateral, and Multilateral), so when coalitions are formed, knowledge is disseminated, and PNs understand the nature of the problem. PNs are at all times encouraged to be physically close in proximity to each other to facilitate information sharing and collaboration [20]. Any nation can initiate contact with SOCOM to become a member. The nature of the GSN is of such flexibility that each PN itself decides how comprehensively it wants to take part in or use the network. Some PNs are members because they need and want support through the GSN membership, while others are because they have SOF capacity and a desire to share the burden within the network. Today the GSN consists of multiple sub-networks that together create the overall network. The main sub-networks are:

- The USA SOF network

- The USA interagency network

- The PN SOF network

- The Geographic Combatant Commands (GCC) and Functional Combatant Commands (FCC) networks

- The Theater Special Operations Command (TSOC) network

- NATO SOF network.

The list does not represent all the sub-networks of the GSN. However, these sub-networks are the most prominent at the interorganizational level [17].

One of the most difficult challenges so far has been the information assurance coordination between the different agencies and military representatives from the PNs. Each country has a national agenda and legislative systems to follow and, on several occasions, there have been challenges as to how to implement and share information both to and from certain PNs due to legal restrictions in information management. To meet the level of information sharing needed within GSN, the classified information sharing system BICES-X was leveraged. It was developed from the NATO Battlefield Information Collection and 
Exploitation System (BICES). This system offers potential solutions to information sharing; however, limitations in the distribution of the system exist, as it is a chain of command (top-down) distributed system. Regardless, the system and the network proved their value in July 2014, as will be discussed in the next section, when the first phases of what were to become Operation Inherent Resolve (OIR) kicked off (Figure 1). Figure 1 depicts the lines of communication in the system and clearly underlines the importance and functions of the GSN [21]. In addition, the BICES system provides the ability to establish live video teleconferences (VTCs) between national headquarters and forward operating bases, as well as joint and NATO headquarters. This unique capability provides members of and commanders within the GSN to have live-feed, secure conversations in support of ongoing missions. On a regular basis, all LNOs need to communicate with national headquarters to get additional guidance. SOCOM has, on this matter, provided facilities for national reach-back, where every nation can install secure national communications systems. This opportunity reinforces and supplements the reach-back capabilities provided by the different nations in the "Coalition Village" at United States Central Command (CENTCOM). Based on the creation of the J3-I and the Global Mission Support Center (GMSC) at SOCOM, it appears that SOCOM has adopted a form of Network Administrative Organization for the overall network. SOCOM facilitates and synchronizes the day-to-day management of Global Mission Support through a focus on strategic/global involvement [17]. The GMSC provides daily and weekly coordination, with the opportunity for deepdive orientations for the Commander SOCOM on a regular basis, all with PN presence. The process is managed and supported by the J3-I through the Campaign Synchronization Process. Based on strategic inputs, a three-year operation cycle is developed. Complicating the process are the different timelines each PN sub-network operates under, the challenge of coordination with each national headquarters, and conflicting governmental guidance.

\section{Maintaining the Initiative}

As command of SOCOM transitioned from Admiral McRaven to
General Joseph L. Votel in August 2014, adjustments and changes to the structure of SOCOM were implemented, with some impacting the GSN and PN representation at the headquarters. In his first opportunity to address the House Armed Services Committee Subcommittee on Emerging Threats and Capabilities as the $10^{\text {th }}$ Commander of SOCOM, General Votel emphasized the following:

We are living in a hyper-connected world; the spread of technology into an increasing number of cultures and societies is driving change in the strategic environment. The Cold War suppressed political mobilization in a variety of ways. The removal of those constraints, coupled with technology, is creating both challenges and opportunities. Adversaries can now easily access tools that range from advanced weapons systems and cyber capabilities ... By increasing transparency, communication, and collaboration with our partners, we maximize the effectiveness of our collective action against shared problem sets. SOCOM will continue to invest in these relationships so that our network development outpaces that of threat networks [22].

This statement, given on March 18, 2015, wrapped up the ongoing process and described the coalition now operating in OIR. Technology and the GSN paved the way for continued PN representation and integration at SOCOM. Lead planners and coordinating events were covered by PN LOs/staff officers within J3-I. By using the existing representation at SOCOM, the leadership set an example of how integration should be done. Initial phases of OIR were Special Operations Command Central (SOCCENT) led; however, CENTCOM was soon to become the lead in what developed into a long-term fight against terrorist organizations in the Middle East. The future of OIR will depend on the new strategic guidance given by the next commander of CENTCOM, General Votel, currently serving as Commander SOCOM. His experience with SOF and knowledge of fighting a network will definitely be added value in fighting Daesh.

\section{The Challenges of Creating a Coalition}

A nation's specific reason for participating in a specific operation

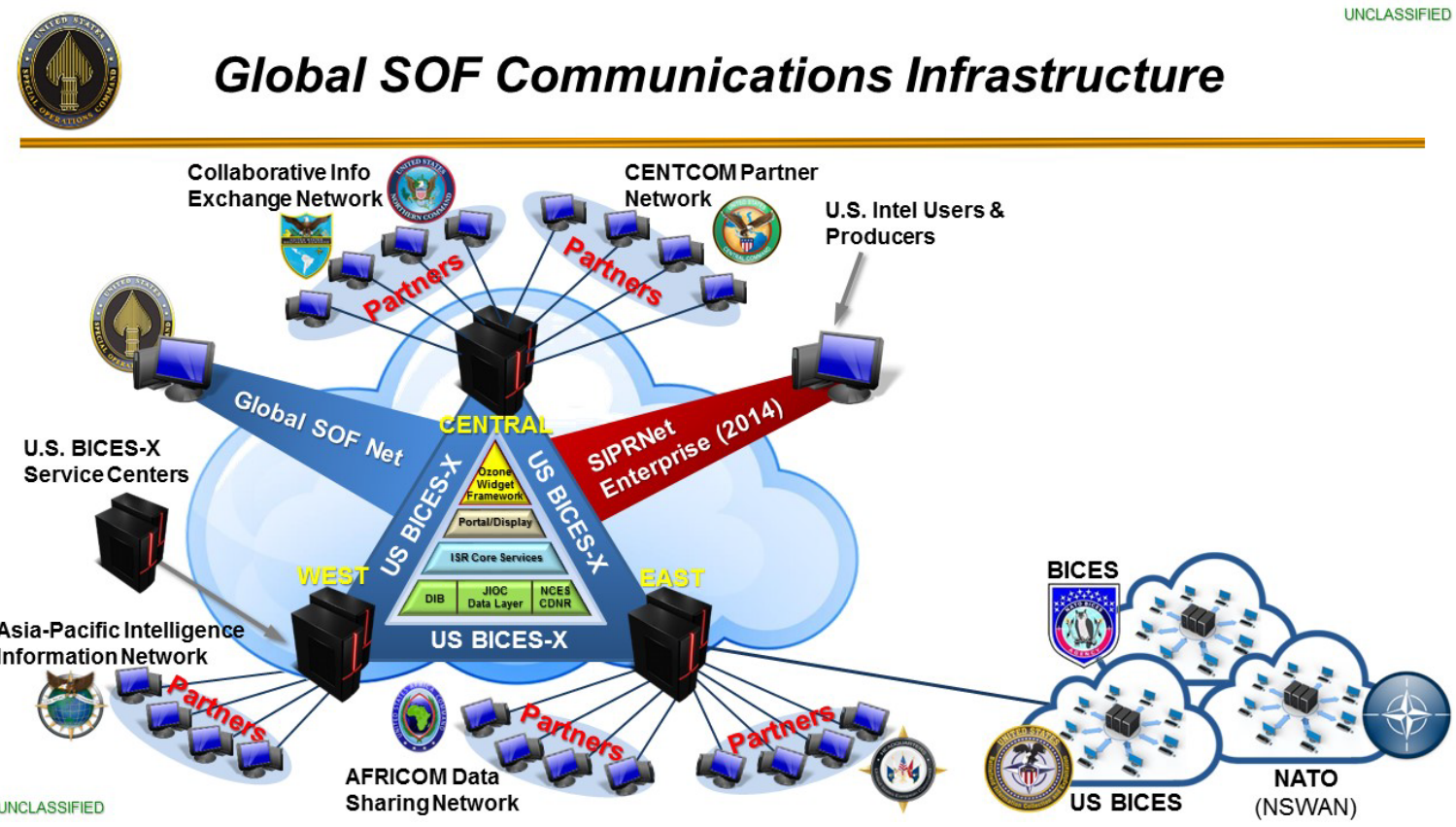

Figure 1: The Global Special Operations Forces Communications Infrastructure. 
or a mission can affect its commitment. It is therefore important to establish informal communities of interest and formal communities of action. In the GSN, these take the form of working groups facilitated by J3-I that can develop and foster PN contributions to mission-specific tasks. In the early stages of any operation, and in OIR specifically, knowledge and reporting of updated information to respective headquarters are essential; it is necessary to provide actionable information to national stakeholders and policy-making politicians.

A challenge in fulfilling this requirement, as previously mentioned, is interagency cooperation. Intel-related information sharing has proven to be a slow process in SOCOM, where only the USA has the capability to distribute information bilaterally or within closed communities such as the Five Eyes Alliance (FVEY) consisting of Australia, Canada, New Zealand, United Kingdom, and the United States [23]. The FVEY environment, best described by the fugitive former NSA contractor Edward Snowden as a "supra-national intelligence organization that doesn't answer to the laws of its own countries," lives its own life. For other PNs, information has, in many cases, been over-classified, and Foreign Disclosure Officers (FDO), or the lack of sufficient FDOs, have severely slowed down the release process [15]. There is an educational gap in classification guidance at the operational level, leaving staff not fully trained in the use of appropriate classification. The Middle East Stabilization Force (MESF) tetragraph was created to ensure inclusion of all PNs involved in OIR; however, the tetragraph was not always effectively used due to lack of will or skill [15]. SOCCENT representatives commented on several occasions throughout the coalition building process that information sharing does not begin until the commander, the J3-I, and authors of plans, orders, and briefing products embrace the information-sharing mindset and begin classifying documents and products for release within the MESF and other offices [15].

For PN LNOs in support of OIR, it has become hard to incorporate lessons learned about Daesh's tactics, techniques, and procedures when classification issues prevent them from being shared. USA. Army Major General Michael K. Nagata, Commander SOCCENT, expressed his guidelines on information sharing to the entire Combined Joint Special Operation Interagency Task Force (CJIATF) during a VTC: "If you have included everyone on your email, CC in some more" [24]. Until this issue of information sharing is resolved, it will be difficult to operate as a coalition.

A recurring issue identified by both USA and PN officers when creating a coalition is the strained integration between conventional forces (CF) and SOF. Barriers to communication materialized as conflicts over command and control $\left(\mathrm{C}^{2}\right)$, rooted in lack of $\mathrm{CF}$ understanding of SOF capabilities [16]. Another problem is when it appears that SOF developed relationships with PNs before CF had an opportunity to do so. This is due to pre-existing relationships with PN SOF; many PNs have experienced the same challenges working with their own CF. Since the space between SOF leaders and national leadership may be compressed, decisions for SOF can be made quicker, and that speed creates a perception that SOF were building their own coalition. These challenges in building a coalition can be addressed by educating CF in the capacities of SOF and how they are synchronized as a part of GCC's efforts.

When establishing a coalition, there will always be jurisdictional challenges until the coalition is finalized. For example, the creation of the OIR coalition was different than the creation of the coalition for Operation Enduring Freedom (OEF) in Afghanistan. OEF later developed the International Security Assistance Force (ISAF), which is governed by NATO directives. The OIR coalition was formed outside of a formal alliance construct, so PNs were not able to fit their contributions into a template or existing structure. When forming new coalitions, new structures must be created and supported. To increase effectiveness, planners must be proactive and define billets and roles concretely.

OIR was created with a non-doctrinal approach to $C^{2}$ structure, resulting in confusion and difficulties explaining current OIR $\mathrm{C}^{2}$ to national military leaders. It is recommended that organizational structure be clearly articulated for operations at all levels, in accordance with Joint Publication (JP) 3-0: Joint Operations and JP 3-05: Special Operations when conducting joint missions or establishing a coalition. In addition, a structural framework for PN billets needs to be developed, such as the one that was initiated in Afghanistan in 2015.

Early deployment of PN SOF representatives to OIR created an opportunity for initial multinational engagements as new partners wanted to join. To work through the concept of troop contribution, the OIR Joint Planning Group (JPG) addressed issues within J3-I to prevent problems and overlying capacities. The broad knowledge of the international personnel at J3-I prevented mistakes and solved ongoing challenges on the front end. Informal discussions among planners allowed them to develop best practices within the legal framework and advise their governments.

Preparations and coordination once deployed for OIR were done through the smart use of reception, staging, onward movement, and integration (RSO\&I). PN integration teams demonstrated success and led newer partners as the coalition began to build solid proof of the efficiency of the GSN in practice. RSO and I was supported both by USA and coalition partners, making the transition of personnel and goods flexible and precise. One of the main contributing factors for the success of integration and the acceleration of the planning process was the collocation of the J3-I and OIR JPG at SOCOM. As SOCCENT was the lead on OIR, but lacked the facilities for planning coali-tion operations, the purpose-built J3-I workspace became the hub for coalition SOF activity. By working out of existing infra-structure and the GSN, planning will have "a warm start for any contingenc [16].

A living network, proactive rather than reactive, has proven the importance of developing the GSN. Access into the SOCOM building is granted for LNOs and is more manageable for PNs than engagements with CENTCOM, as it belongs to a different GCC. A major drawback is that $\mathrm{PN}$ presence at SOCCENT is not currently possible, as the building is a Sensitive Compartmented Information Facility (SCIF)-TSOCs are not built or equipped to host coalition planning efforts [16]. It is likely that the US facilities will continue to have a rating of "No Foreign" for the foreseeable future.

Coalitions must facilitate entry of new partners based on requirements, not based on convenience of previous partnerships or agreements. An example of this is the fight against Daesh. While the regional problem is based in Syria, many nations have focused on supporting efforts in fighting the adversary in Iraq. This is mostly out of political convenience and also because in Iraq there were previously established Status of Forces Agreements (SOFA). In the future, it is likely that several additional nations will join CJIATF-Syria in order to keep the pressure on Daesh. There must be a way to expand the partnership so that it is the most operationally effective rather than the most politically expedient.

Since SOCOM and CENTCOM belong to two different structures, with overlapping operational areas, participants have discovered 
challenges in the LNO structure within the two commands. Since many SOF LNOs are junior in rank to their respective countries' Senior National Representatives (SNR), all communication and reachback must be coordinated to avoid confusion that can arise from reports written and submitted by two different people. SOF lines of communication are often short, and representatives will in many cases report directly to strategic military and political leadership in PN countries. It is therefore important to know and clarify how SOF fits into the CENTCOM SNR network, and to clarify national caveats, political sensitivity, and limitations. CENTCOM was responsible for building a coalition during OIR; SOF forces on the other hand were already engaged in Iraq, causing uncertainty among planners about who was building the coalition. SNRs were, on several occasions, approached by CENTCOM without including SOF in the planning. CENTCOM needs to understand that SNRs are sometimes not connected to SOF, due to national defense structures [16].

During OIR development, most nations needed a whole-ofgovernment approach to the new line of operations, more than a CFversus-SOF approach as the $\mathrm{C}^{2}$ structure represented in the initial phase. The lack of protocol and doctrine on how to establish a coalition has been immense. As stated by Commander NORSOCOM, Rear Admiral Holte, "Operational requirements often outpace established doctrine, relationships, and agreements. This can result in operations that require the establishment of a coalition that may not be properly resourced or planned-especially at the strategic level" [25]. For future operations, integrated planners on both a permanent and case-by-case basis should be accommodated by SOCOM in order to handle the workload that creating a "coalition of the willing" requires. Having temporary planners present will lend long-term, big-picture values to the JPGs, as LNOs have to deal with several additional duties, both as LNOs and as exchange officers.

With PN SOF representatives in theater, the GSN began working on a new line of approach. Forces assigned to Special Operations Joint Task Force-Iraq (SOJTF-I), significantly, provided new and timely information to national headquarters and J3-I. This dramatically reduced the number of requests for information (RFI) previously fielded by SOCCENT teams. Additionally, partner LNO workload at SOCOM decreased significantly, as the partner HQ questions could be answered by those partners deployed on the ground. The PN deployment of planners and staff officers from national SOCOM structures forward provided new (PN-influenced) situational awareness with key figures for the JPG VTC meetings at SOCOM.

These opportunities adjusted PN expectations and provided more precise information on which capabilities were needed in OIR. The broadening of the GSN accelerated this process and resulted in greater efficiency and budget reductions. In an early stage of OIR, best practices resulted in SOJTF-I being granted permission to write reports for MESF release, and this information sharing ended the initial challenge of many reports being overclassified. While working in a coalition, many nations are accustomed to stamping every report with the SECRET/NOFORN classification, and breaking this habit will take time. However, the change has already enhanced information sharing, and reports from several countries have been provided to the OIR JPG. The main communication system in this effort was still the BICES system, reinforced by BICES professionals solving initial technical challenges. It is recommended for future operations that there be PN presences on SOF staff forward, with national and NATO communication systems, to improve planning prior to the deployment of the main body of any coalition partners.

\section{Coalition of the Willing}

In the aftermath of the deployment of both CF and SOF to OIR, SOCOM and PNs have achieved well-coordinated and combat-proven integrated campaigning with partners. Skeptics, like Foreign Policy reporter Paul McLeary, have seen the rise of the GSN as controversial, even though it provides a common basis for SOF in a new environment [26]. The GSN has proven its value in support of CF, preparing the battlefield and providing common knowledge through PN deployments and staff officers serving in joint staffs. The cultural differences between PNs and the USA in the GSN become more visible once members are deployed, rather than operating in an everyday situation at SOCOM. A joint recce was conducted by representatives from The Netherlands, Spain, and Norway. This clarified the different authorities and SOFAs the different countries had with the government of Iraq. The largest difference, however, appears between the IA intelligence community and SOF. SOF operations require high-resolution intelligence, hence the importance of trust between the communities. Whereas SOF are deployed to conduct operations on the ground, intel analysts are provided safe and secure environments, focusing on doctrinal work and collection. Every SOF operator is willing to go above and beyond the call of duty to solve a mission. An intelligence analyst, however, needs to prioritize among requirements and customers, and will in many cases resist revealing information without exchange and prior concurrence from higher headquarters [17]. A continuation of cooperation between IA operators and SOF will leverage operational experience of new technology and collection assets. It is needed and recommended that deployed forces view their role both within the GSN, and perhaps more importantly, the larger CF and IA environment. SOF and CF members are a part of the larger puzzle, the complex and evolving concept of war, which affects every soldier and nation participating in a conflict. Burden sharing and serving one's nation for a common interest creates a network of trust larger than any single nation is capable of building.

OIR has demonstrated that small nations' cooperation with the USA can be timely, efficient, and cost-effective. The GSN can enable quick reaction time and rely on the whole network for support in a crisis response situation. This can include a variety of options, such as strategic lift assets, intelligence sharing, operational support, and strategic surveillance capabilities. Several PNs have experienced new challenges during OIR, and it is important for SOF commanders to expand their audience and to continue to educate military and political leaders on how to best deploy and employ SOF power in a dynamic environment. Political decision makers need to understand the importance of the GSN and how to efficiently use SOF.

\section{Recommendations and Conclusion}

The continued development of SOF partners within SOCOM is depicted below. A steadfast growth in the coming years is likely to establish a PN presence with more than seventy countries, though this could become somewhat unwieldy if not tailored for more efficient partnering. Figure 2 gives an overview of the growth of SOF partnerships within SOCOM.

The expansion of PN representation at SOCOM depicted in Figure 2 is likely to result in two significant challenges [17]. The first will be a perception of freeriding by smaller nations on the backs of large, mature, SOF-capable states. The purpose of sending representatives to SOCOM is not to improve current operations, but to get out in front of current operations in order to be better positioned, networked, resourced, and postured to defeat adversaries before they have the initiative, or to confront them from a position of superiority. Since 


\section{U United States Special Operations Command}

\section{J3-International SOF Partnerships}
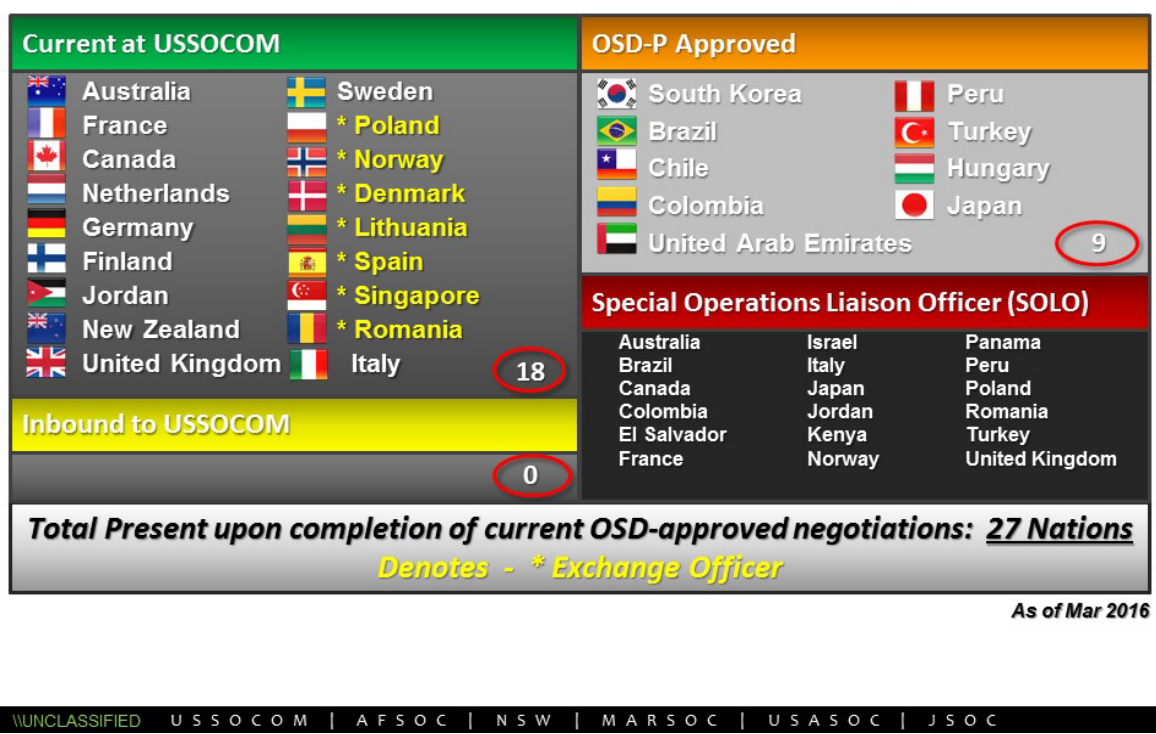

Figure 2: The Growth of SOF Partnerships within SOCOM.

SOCOM does not conduct tactical operations, small nations should consider if an LNO position within a TSOC is of higher value, due to proximity and operational experience needed for the individual country. Limitations on access from the USA side may restrict this possibility. US military decision makers must not provide mixed signals to PNs when suggesting coalitions. Information sharing with PNs must be a primary consideration to avoid bottlenecks created by inability to share sensitive information critical to mission success.

Second, by expanding PN presence, the GSN might lose some of its value. If too many nations are included, what are the benefits to the individual nation? "The perception of being valued and treated as special is important for participation in any network" [27]. These challenges should be considered by PNs in the GSN when enthusiastically contributing to the Global SOF Enterprise.

In view of these challenges, a beneficial step for the GSN to take would be to define the organizational structure and clearly articulate it for operations at all levels, in accordance with JP 3-0: Joint Operations and JP 3-05: Special Operations when conducting integrated campaigning with partners. In addition, a structural framework for PN billets needs to be developed within SOCOM. Integration of PN LNOs in forwarddeployed staff billets similar to OIR needs to continue and expand. Benefits of this will be seen as the OIR coalition develops situational awareness and achieves success in training the indigenous population, and when CJIATF - (Iraq and Syria) exploits gaps and friction, creating a stronger coalition prepared to fight Daesh in both Iraq and Syria. The network connections that are established through the GSN will enhance such a development as military advisors and leaders give their advice to political leaders. Continuing development of the BICES system will enhance GSN and SOF capabilities and accommodate coordination between nations in support of the Global SOF Enterprise. The implementation of BICES as a supportive SOF system by NSCC/ NSHQ has made way for technological development and built bridges over old-fashioned obstacles protected by the descendants of the men with "cloaks and daggers."

\section{Acknowledgments}

The views expressed in this publication are entirely those of the authors and do not necessarily reflect the views, policy or position of the Norwegian Army Special Operations Commando (NORASOC), the Norwegian Armed Forces, the Norwegian Defence University College, the United States Government, the Department of Defense, the United States Special Operations Command, or the Joint Special Operations University.

\section{References}

1. Dictionary.com. (2017) Daesh.

2. Myklebust G (2011) Tungtvanns-Sabotøren (The heavy water saboteur). Oslo: Aschehoug.

3. Waller D (2015) Disciples. Simon \& Schuster, New York.

4. Forbath P, Colby C (1978) Honorable Men: My Life in the CIA. Simon \& Schuster, New York.

5. Kristoffersen E (2015) Small States-Smart Solutions: Investing in a Nationa Joint Special Operations Command. Master's thesis. Carlisle, PA: United States Army War College.

6. Forsvaret (2016) Forsvarets Spesialstyrker.

7. USSOCOM (2017) SOF Truths, JSOU (SOF Reference Manual1-1).

8. Army John F. Kennedy Special Warfare Center and School (2012) Q\&A with Admiral McRaven. Special Warfare, 25: 10-11.

9. Gray CS (1999) Handfuls of Heroes on Desperate Ventures: When Do Special Operations Succeed? Carlisle, PA: United States Army War College.

10. Docauer A (2014) Peeling the Onion: Why Centralized Control/Decentralized Execution Works. Air \& Space Power J.

11. McRaven WH (2013) Admiral and Commander, USSOC, Posture Statement before the 113th Congress House Armed Services Committee.

12. Yoho KD, Knowles Td, Borum R (2014) The Global SOF Network: Posturing Special Operations Forces to Ensure Global Security in the 21st Century. J Strategic Secur 7: 1-7.

13. NATO Home Page (2012) NATO Special Operation Headquarters Officia Opening December 12

14. Lysgard A (2013) Observation as Aide De Camp (ADC) to the Norwegian Chief of Defense. 
Citation: Lysgård A, Boe O (2017) A Partner Perspective on the Evolution of the Global Special Operations Forces Enterprise. Arts Social Sci J 8: 313. doi: $10.4172 / 2151-6200.1000313$

Page 8 of 8

15. Lysgard A (2015) Experience as Norwegian LNO to SOCOM.

16. SOF Lessons Learned Network (2015) Multinational SOF Planning Insights. Tampa 2.

17. Carling J, Kihl TE (2014) The Global Special Operations Forces Network from a Partner-Nation Perspective. Master's thesis. Monterey: Naval Post Graduate School.

18. Arquilla J, Ronfeldt D (1996) The Advent of Netwar. Santa Monica: RAND Monograph Report.

19. Morrison S (2013) Redefining the Indirect Approach, Defining Special Operations Forces (SOF) Power, and the Global Networking of SOF. Journal of Strategic Security 7: 48-54.

20. SOF Lessons Learned Network (2015) (JLLIS 302384 Unclassified Appendix A-3).
21. SOF Lessons Learned Network (2015) (JLLIS 302384 Unclassified Appendix A-11).

22. Votel JL (2015) Statement before House Armed Services Committee Subcommittee on Emerging Threats and Capabilities.

23. Cox J (2012) Canada and the Five Eyes Intelligence Community. Calgary: Canadian Defence and Foreign Affairs Institute.

24. Nagata M (2014) Major General and Commander SOCCENT, BICES VTC J3-I. 25. Holte NJ (2014) Rear Admiral Commander NORSOCOM Tampa.

26. McLeary P (2013) Lawmakers Skeptical of Global Spec Ops Plan.

27. Sunde H (2012) Partnership for Peace assessments. Brussels: NATO. 